\title{
Defining Digital Pedagogy in Theological Libraries
}

Libraries are, at their best, institutions that teach. I often get confused looks when I describe to non-librarians what I do. It seems the general public thinks about librarians as curators and collectors, and so when I talk about how much of my work (and that of my colleagues) involves instruction, whether in a classroom, in a workshop, or at a reference desk, people are surprised. Librarians are teachers; I tend to emphasize Atla's identification of us as "connectors," for I think that holds true for what each of us do. We connect our patrons, be they faculty, students, or staff, with the resources and skills that they need to succeed.

In a digital age, though, just how a library and its librarians implement that instructional identity has come into question. The introduction of new tools, of new sources of information, and of new avenues for scholarly output creates an opportunity for libraries to reassert their essential role in the teaching mission of many theological schools, but the library will only be successful in reasserting this role if librarians carefully consider how teaching must be adapted to the new norms of a digital age. The question in this chapter is how libraries can maintain their instructional identity when the needs of our patrons and the possibilities for scholarly output are changing so quickly.

\section{Attempts to Define Digital Pedagogy}

Consideration of how libraries must adapt instruction in a digital age must begin with the popular term "digital pedagogy." The digital age has introduced us to new and often vague concepts like "digital pedagogy." New ideas are often followed by battles over defining new terms. Consider, for example, the world of scholarship focused on defining the concept "digital humanities." In the minds of many, definitions of that term have become so varied that the term lacks any helpful meaning, not to mention attempts to define the many cognate terms such as "digital scholarship" or "humanities computing."1 Perhaps sur-

1 For discussions of the history of defining this term, see Matthew G. Kirschenbaum, "What Is Digital Humanities and What's It Doing in English Departments?,” ADE Bulletin.150 (2010): 1-7. Melissa Terras, Julianne Nyhan, and Edward Vanhoutte, eds., Defining Digital Humanities: A 
prisingly, though, a definition of the equally-significant term "digital pedagogy" has not been considered as thoroughly. Within recent consideration, emphasis has fallen on each word, with some emphasizing digital pedagogy as a shift in instructional method, while others reading it as a shift in instructional content. The first group emphasizes pedagogy, reading “digital pedagogy” to describe approaches to teaching that incorporate digital methods and tools in the delivery of content. For example, Brian Croxall has defined digital pedagogy as "the use of electronic elements to enhance or to change the experience of education." ${ }^{2}$ Croxall provides examples of digital pedagogy that range from the use of PowerPoint in the classroom to the teaching of massive open online courses (MOOCs). Understood in this way, digital pedagogy means enhancing teaching through the incorporation of digital tools or pedagogical methods made possible through digital technologies. To engage in "digital pedagogy" is to deliver instruction by implementing new digital tools. Under this definition falls the "flipped classroom" and online instruction, as well as the use of videos to deliver instruction or the incorporation of digital exhibits or text mining tools into course assignments.

Operating under this definition, many librarians continue in a traditional instructional support role. That is, participating in "digital pedagogy," the librarian works to convince and aid those who serve in traditional teaching roles to integrate new digital tools into content delivery in the classroom. Librarian support may come in the form of electronic course reserves, managing or training on a school's learning management system, or teaching faculty best practices in online and hybrid course delivery. Studies have shown that through the incorporation of digital tools, students can be more engaged, content can be more effectively delivered, and schools can expand and diversify their student bodies. ${ }^{3}$ Therefore, under this definition, librarians interested in digital pedagogy should ask how they can encourage faculty to incorporate new tools and methods to enhance the classroom experience.

Reader (Surrey: Ashgate, 2013). David M. Berry and Anders Fagerjord, Digital Humanities: Knowledge and Critique in a Digital Age (Cambridge, UK: Polity Press, 2017).

2 Brian Croxall, “'Digital Pedagogy’?,” A Digital Pedagogy Unconference, August 30, 2012, http:// www.briancroxall.net/digitalpedagogy/what-is-digital-pedagogy/. For a similar understanding of the term digital pedagogy, see Myra Waddell and Elena Clariza, "Critical Digital Pedagogy and Cultural Sensitivity in the Library Classroom: Infographics and Digital Storytelling," College \& Research Libraries News 79.5 (2018): 228-32.

3 For examples of studies highlighting the benefits of integrating digital tools into traditional courses, see Deborah Tritt and Carie Heatherly, "Practitioners as Professors: Experiential Learning in the Distance Digital Liberal Arts Classroom," College \& Undergraduate Libraries 24.2-4 (2017): 545-58. Hannah Jacobs, "Collaborative Teaching and Digital Visualization in an Art History Classroom,” Visual Resources Association Bulletin 43.2 (2016): 1-11. 
As opposed to that instrumentalist view of "digital pedagogy," where the digital enhances the mode of instructional delivery, some have defined "digital pedagogy" by emphasizing new content as the focus of instruction. That is, some understand the digital as the object of the pedagogy, enacting "digital pedagogy" as equipping students to live, work, and produce scholarship in a digital age. In this mode, an instructor shifts his or her focus to teach the skills and methods popular in the digital age so as to prepare students to live and work in a world that is defined not only by new tools, but by new modes of thinking, reading, and communicating. Methods of teaching with this understanding may range from direct instruction in digital tools to opening the possibility of digital humanities projects as student output. Stewart Varner understands "digital pedagogy" in this way when he notes, "Librarians would do well to expand their concept of instruction to include the ability to find, evaluate, and learn to use new tools for exploring, sharing, reusing, and remixing research materials."4

Operating with this definition, the librarian is often in a more direct teaching mode, as the instruction on digital tools and methods is often viewed as paracurricular. A school or program must continue to deliver its traditional content, and so the library is asked to supplement course offerings with workshops designed to teach students the skills and tools to succeed in a digital age. The librarian, therefore, is invited to see his or her job to be the facilitating of the introduction of new tools into the classroom, allowing instructors to teach their students in new ways.

Readers will likely agree on the import of both understandings of "digital pedagogy." Librarians should certainly not be forced into choosing one or the other, and instead should embrace both new methods of teaching and new content to be taught as an opportunity to increase their impact on campus. In this essay, though, I try to hold these two together by arguing that digital pedagogy should not be limited by defining it in either way. That is, I emphasize how libraries can introduce digital tools to enhance the teaching that is happening at our institutions, and at the same time encourage librarians to train patrons who are more equipped to operate in a digital world.

Librarians need to think about how we are teaching and what outcomes we are looking for, before we focus on the specific tools we are introducing. My argument is in line with Paul Fyfe's concern that, "Perhaps the most common short-

4 Stewart Varner, "Library Instruction for Digital Humanities Pedagogy in Undergraduate Classes," Laying the Foundation: Digital Humanities in Academic Libraries, ed. John W. White and Heather Gilbert (West Lafayette, IN: Purdue University Press, 2016). 
coming of digital pedagogy is how frequently it gets conceived in terms of instructional technology." ${ }^{5}$ Likewise, Jesse Stommel argues, "Digital pedagogy is an orientation toward pedagogy that does not fetishize digital tools."6 Like so many other aspects of our approach to the digital age, we librarians in our instruction run the risk of taking an instrumentalist view of technology, of equating the changes in our digital age with the introduction of the electronic tools that surround us.

My central argument is that libraries have an essential role to play in digital pedagogy, and that role goes far beyond introducing students and faculty to the latest tools. Rather, libraries must see their mission as developing patrons' skills to think critically about what new tools, ideas, and methods are doing to communication and how we can best take advantage of them to maximize impact.

\section{The Danger of the Status Quo}

To make this argument about the library's role in digital pedagogy, I begin in a descriptive mode, considering how libraries are currently teaching in the digital age. In looking at the literature about digital pedagogy and libraries, I find much that concerns me about the way libraries have entered the digital age in terms of their teaching.

John Russell and Merinda Kaye Hensley, in a December 2017 piece in College and Research Libraries News, capture well my concern about how librarians have approached teaching tools and methods for the digital humanities. Russell and Hensley warn against a focus on "buttonology," a term they define as follows: "There is a danger with digital humanities instruction of falling into the trap of buttonology. By buttonology, we do not mean the study of buttons. . . . Buttonology is, in its simplest terms, software training that surveys different features of an interface in an introductory manner."7 Many librarians likely recognize a "buttonology" approach to the teaching or learning of digital humanities. Most have been invited to or attended countless Voyant or StoryMap JS sessions offered in libraries, sessions which emphasize how to use this or that particular tool, but with little focus on the context for why the tool is needed, the practical problem

5 Paul Fyfe, “Digital Pedagogy Unplugged,” DHQ 5:3 (2011), http://www.digitalhumanities.org/ dhq/vol/5/3/000106/000106.html.

6 https://www.tiki-toki.com/timeline/entry/392826/Digital-Pedagogy-a-Genealogy/

7 John E. Russell and Merinda Kaye Hensley, "Beyond Buttonology: Digital Humanities, Digital Pedagogy, and the ACRL Framework," College and Research Libraries News 78.11 (2017): 588. 
that one might use the tool to solve, and how engagement in scholarship on a digital platform creates new opportunities and challenges.

Russell and Hensley continue by noting that library literature on digital humanities pedagogy tends to be "practical, with a focus on how best to present digital tools." A quick search of the library literature, particularly in the field of theological librarianship, confirms this, with reports of workshops and instructional sessions seemingly designed to give users a crash course in this particular tool or the next.

I do not here offer a blanket critique of workshops as a form of library instruction, even workshops on digital tools. I work in a library that offers dozens of instructional sessions on a range of tools, such as Accordance, Zotero, Voyant, and StoryMap, and these are very effective ways to open students' eyes to new capacities for research and communication in a digital age. Where else are students going to learn these new tools that are going to be essential in their future work?

However, I share the critique of the buttonology approach to the digital humanities in library instruction if these workshops are librarians' singular attempts at instruction in a digital age. Such a limited approach to digital pedagogy represents a missed opportunity for libraries, but more importantly it falls short of teaching our patrons what they need in order to succeed in the digital world. I find flawed an approach that begins by outlining the use of a tool, assuming a student will place this tool in his or her toolkit and eventually find a problem that the tool solves. All of our patrons face an overload of new ideas, concepts, and methods, and the library's buttonology approach simply places the new tool, even something as helpful as Voyant, as one more thing to learn.

A close parallel to this buttonology approach to digital tools, one which I also find flawed, is books that introduce various modes of biblical exegesis, without first introducing the problems these methods of exegesis seek to answer. Consider, for example, the organization of one popular exegesis book into separate chapters that identify one mode of criticism after another. ${ }^{9}$ First a student learns of textual criticism, then form criticism, then redaction criticism. Multiple modes of taking apart a text are presented to the student as a range of options for how one can get started with writing an exegesis paper. What is missing, though, is an introduction to the problems in the biblical texts that these different modes of exegesis sought to answer when they were first introduced. The reader is never

8 Russell and Hensley, "Beyond Buttonology,” 588.

9 See John H. Hayes and Carl R. Holladay, Biblical Exegesis: A Beginner's Handbook, 3rd Edition (Louisville: Westminster John Knox Press, 2007). 
invited to consider, for example, that Rudolf Bultmann did not engage in form criticism because it was the particular method he learned about in a workshop. Rather, he engaged in form criticism because he started to recognize a basic pattern in the pronouncement stories in Matthew's gospel and was curious how these might have developed and what their development might tell us about earliest Christianity.

In a similar way, I often find introductions to various tools used by digital humanists to be an ineffective way of introducing our patrons, be they students or faculty, to the power of new methods of scholarship. The challenge of this buttonology approach to teaching the digital humanities is that our patrons may not yet have problems to which these tools are offered as solutions. This buttonology approach, understanding digital instruction as equipping students with tools to eventually employ, is a first problem I identify with what we have been doing in our workshop approach to the tools of digital humanities. We offer solutions to problems that our patrons have not yet identified.

There is a second, and in many ways deeper, problem with a workshop approach to the tools of digital humanities. Typical approaches to digital pedagogy reflect an instrumentalist view of technology, one which has been identified as problematic at least since the early twentieth century and the work of key philosophers of technology, notably Martin Heidegger. ${ }^{10}$ A buttonology approach would suggest that the digital age has gifted us with some new ways of doing scholarship, and all one needs to do is learn the new tools. So, while a key example of scholarly output was previously a twenty-page exegetical essay, it is now an audio/visual timeline constructed online. With such an approach, we offer students no space to reflect critically on how new tools change our scholarly communities, what opportunities they open up for reaching new audiences, and the problems, be they ethical or practical, the use of such tools might create.

To this point, my argument has largely been a negative one-critiquing what I find lacking in librarians' approaches to digital pedagogy. What solutions do I offer? I do not intend to suggest there is a single silver bullet for how libraries should approach the introduction of the digital age to the classroom. I do, however, offer a few guiding principles, with some examples of how they have been implemented, as an opening for a conversation about what critical digital peda-

10 See Martin Heidegger, “The Question Concerning Technology,” in Basic Writings, Revised, Expanded Edition, Harper Perennial Modern Thought (New York: Harper Collins, 2008), 307-41. For expanded analysis, see Ivan Illich, In the Vineyard of the Text: A Commentary to Hugh's Didascalicon (Chicago: University of Chicago Press, 1996); Elaine Graham, "Being, Making and Imagining: Toward a Practical Theology of Technology,” Culture and Religion 10.2 (2009): 221-36. 
gogy might look like in the theological library. I briefly introduce these here in hopes that they are generative of reflection for you in others' particular contexts.

\section{All Library Instruction Should Combine the Practical with the Reflective}

The idea that tools are not neutral, and thus the adoption of new tools creates the potential for introducing new bias, is something we all likely recognize inherently. However, the ubiquity of digital tools in our daily lives demands that libraries equip students to think critically about who is controlling our information and what role we are playing in the information ecology. If we simply lay more tools at our patrons' feet, we become part of the problem rather than the solution. For example, I often ask my students to tell me why the Waze app on their phone invites them to turn left rather than turn right on their way to a destination, and they are often dumbfounded to even consider this as a question. The "why" behind an algorithm is not a natural question to my students. ${ }^{11}$ As librarians, therefore, when we introduce even more digital tools into our patrons' lives, we carry the obligation to start these conversations about the complex tradeoffs between convenience and privacy that we make every day.

The ACRL Framework for Information Literacy is a helpful model for introducing such a critical element into our digital pedagogy. ${ }^{12}$ Just as the framework encourages librarians to train students to recognize that authority in bibliographic sources is constructed and contextual, so we must train students that their adoption of various tools is not a neutral act and will likely have unintended consequences for their scholarship, their community, or their congregations. The convenience and power of digital tools, facts that are so often the focus of the buttonology approach to teaching digital tools, come with many downsides, and it is our job to ensure that our students have considered the tradeoffs they are making when choosing new tools. While patrons may benefit from the convenience of using a service like MailChimp to maintain a mailing list and facilitate mass communication, they are also exposing themselves to the vulnerability of trusting an unknown vendor with securing the privacy of those with whom they communicate. If we as librarians do not invite students to recognize this

11 There have been a number of important works analyzing the biases built into the algorithms of our ubiquitous digital tools. For a supreme example, see Safiya Noble, Algorithms of Oppression: How Search Engines Reinforce Racism (New York: NYU Press, 2018).

12 http://www.ala.org/acrl/standards/ilframework. 
tradeoff, we not only fail to live up to the standards of the framework, but we have not truly taught our patrons to thrive in a digital age.

Fortunately, many of us work and are trained in a discipline that has thousands of years of examples of engagement with technology. Much as our students may think the challenges of the digital age are new, church history is screaming with examples of adapting to new tools and methods. I often use the example of the broadcast of sermons on the radio in the early twentieth century. Sermon broadcasts were initially quite successful in the white church, but less so in the black church. Jonathan Walton, in his book Watch This, documenting the history of black televangelism, offers an explanation: "The first preacher recorded on a major label was Rev. Calvin P. Dixon in 1925. Columbia [Records]'s race series inaugural religious effort, however, did not make a great splash among targeted consumers.... The sole emphasis was on Dixon's sermon, yet a preacher constitutes only one part of the Du Boisian descriptive trinity of 'the Preacher, the Music and the Frenzy." 13 The shift in medium changed the message, and the church had to adapt its use of the growing technology in order to best meet its goals. This analysis is the type of critical engagement for which our students must be equipped. Just as Walton's analysis suggests that the church would not have been well-served by generic introductions to the use of the radio to disseminate sermons, so our patrons are not well-served by workshops simply introducing them to new possibilities offered by digital tools. Rather, they need to be challenged to recognize that their adoption of new tools is not a neutral act, but rather new tools will by definition change the way they communicate to particular audiences. My concern is that the space for this type of reflection on this rarely exists for our students; I see this as a primary role for digital pedagogy in the library. We must introduce the tools, but we must also invite students to see them as more than tools.

\section{Digital Pedagogy Must Be Deeply Integrated into the Existing Classroom}

As noted above, one of the challenges with a buttonology approach to digital pedagogy is the extra-curricular nature of how it often happens. Often, we inundate our students with the possibilities of various tools, rather than offering the tools as a solution to the specific problem they are seeking to answer.

13 Jonathan L. Walton, Watch This! The Ethics and Aesthetics of Black Televangelism (New York: NYU Press, 2009), 34. 
One remedy to this challenge is to introduce tools and methods within the space of a classroom and replace, rather than add to, what students are asked to do. At my library, we have had great success by working with faculty to replace the traditional exegesis paper, for example, with a digital exhibition or Wikipedia edit, inviting students to take the problem they are already working on and to see the digital tool or method as a way of addressing it. The just-in-time nature of instruction on new tools is essential to grow their adoption rate, and it invites in students the necessary curiosity of asking what other digital tools might be out there. And as we all know, the effective teacher is not the one who effectively trains in some method or tool, but rather the one who sparks the imagination in the student to ask what else is out there.

\section{Successful Digital Pedagogy Equips as Well as Instructs}

Alongside meeting students with digital solutions for problems they are already asking, successful digital pedagogy supports students by helping them tear down the barriers to entry in creating digital projects. These barriers can be technical and knowledge-based, but they can often also be financial. Instruction without a path toward implementation is bound to fail.

We realized this problem at my library quickly when we offered workshops on the creation and curation of one's digital presence. We offered (in my mind) excellent instruction on how to build a WordPress site, but once students realized that they needed to invest some of their money in order to have full access to the range of tools wordpress.org offered, then they quickly forgot what they were learning. We sought to remedy this by introducing a Domain of One's Own program. Here we not only encourage students to develop a web-based project to promote their scholarship or their nonprofit or whatever, but we also provide them server space, a URL, and a set number of hours of consulting to get them started, at a small cost to the library, a cost that would be prohibitive for many of our students.

The barrier may not always be financial. It may be that students are lacking certain technical skills, vocabulary, or experience to increase adoption, and the library can play a role in guiding them toward collaboration partners or introducing them to training opportunities. The point is simply that the library cannot see its pedagogical role to end with the moment of instruction. Rather, the library must equip its patrons to succeed with their implementation of the digital, not 
merely understanding its pedagogical role to end with the introduction or exposure to new tools.

\section{We Must Partner Digital Pedagogy with Digital Scholarship in the Library}

The methods and skills of digital scholarship are difficult to teach in a vacuum, that is without real life examples. Fortunately for us, we all work in libraries, which are themselves platforms for implementing digital approaches and tools. Gone are the days when one could stand by the saying "those who can't do, teach." Methods in digital scholarship demand practitioners be the ones who teach, and they demand opportunities for students who want to put to work what they have learned.

In our library, we have had great success with marrying the instruction of new methods or tools with work opportunities for students to develop those tools based on digital projects ongoing in the library. For example, we have built a Howard Thurman digital audio archive, a project that involves learning digital exhibitions, graphic design, metadata curation, GIS mapping, transcription, etc. ${ }^{14}$ The project has been built not merely by external contractors and library staff, but also with significant support from our student patrons. What better way to teach these skills than to invite students to participate in a project, to learn on the job, and in turn to benefit the library (and build a CV line)? The more libraries can connect an actual output of digital scholarship with digital pedagogy, the more successful they will be.

\section{A Better Way Forward}

I close with a return to the question of definition of the term "digital pedagogy." Is it using digital tools to teach, or is it teaching digital tools? I hope that you see that I believe it is both. That is, “digital pedagogy” means opening up patrons' minds to the power of the tools and methods of the digital age, sparking their creativity to critically engage this digital world in their learning and their creating. The outcome may be that patrons are emboldened to use digital tools in their scholarship or their teaching, or it may be that they take a more careful and critical approach to the digital tools that surround them. Either way, our job as li-

14 See http://thurman.pitts.emory.edu. 
brarians engaged in digital pedagogy is to introduce patrons to a new mode of critical thinking, open to the introduction of new tools, supported with the resources to learn to use them, and cognizant of the implications the adoption of these tools may have.

Why should we introduce digital pedagogy into our library instruction? I emphasize to my colleagues that digital pedagogy is not simply an opportunity for the library to find something to do, to show its value to the institution. Rather, I find it to be a moral obligation, to ensure our students can enter into this digital age equipped not only to build things like websites, but also to think critically about how their building may impact their work. Most of my students are M.Div.s, often on the younger end of the scale. I imagine (and have heard) that she is going to walk into her first congregational call with all eyes upon her as the "young person" who by default is asked to rebuild the church website, manage the live streaming, and oversee social media. My goal in teaching is not only to equip her with the skills she needs to do those things and the places to go to learn what she doesn't know, but also to embolden her to think carefully about why the church may or may not need these tools and what impact they will have on her ministry.

The role of critical digital pedagogy is essential, and I fear that if the library isn’t going to do it, it isn’t going to be done. 
